\title{
Role of triosephosphate isomerase and downstream functional genes on gastric cancer
}

\author{
TINGTING CHEN $^{1 *}$, ZHIGANG HUANG $^{1,2^{*}}$, YUNXIAO TIAN $^{3}$, HAIWEI WANG $^{3}$,

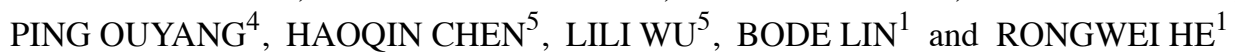

${ }^{1}$ Department of Epidemiology and Health Statistics, School of Public Health, Guangdong Medical University, Dongguan, Guangdong; ${ }^{2}$ Dongguan Key Laboratory of Environmental Medicine, Dongguan, Guangdong; ${ }^{3}$ Department of Pathology, Handan Central Hospital, Handan, Hebei; ${ }^{4}$ Scientific Research Centre, Guangdong Medical University, Dongguan, Guangdong; ${ }^{5}$ Department of Internal Medicine, Dalang Hospital of Dongguan City, Dongguan, Guangdong, P.R. China

Received April 11, 2017; Accepted July 14, 2017

DOI: $10.3892 /$ or.2017.5846

\begin{abstract}
Triosephosphate isomerase (TPI) is highly expressed in many types of human tumors and is involved in migration and invasion of cancer cells. However, TPI clinicopathological significance and malignant function in gastric cancer (GC) have not been well defined. The present study aimed to examine TPI expression in GC tissue and its biological functions. Furthermore, we investigated its downstream genes by gene chip technology. Our results showed that TPI expression was higher in gastric cancer tissues than adjacent tissues, although no statistical differences were found between TPI expression and clinicopathological factors. TPI overexpression in human gastric carcinoma cell line BGC-823 enhanced cell proliferation, invasion and migration, but did not change cell cycle distribution, while TPI knockdown suppressed proliferation, invasion and migration, induced apoptosis and increased G2/M arrest of human gastric carcinoma cell line MGC-803. Since the cell division cycle associated 5 (CDCA5) was identified as the one with the most decreased expression after TPI knockdown, we investigated its role in MGC-803 cells. The results showed that CDCA5 knockdown also inhibited proliferation, migration, induced apoptosis and increased $\mathrm{G} 2 / \mathrm{M}$ arrest similarly to TPI knockdown. CDCA5 overexpression promoted MGC-803 cell proliferation, clone formation and migration abilities. These results indicated that TPI expression level might affect GC cell behavior, suggesting that both TPI and CDCA5 might be considered as potential tumor markers
\end{abstract}

Correspondence to: Zhigang Huang, Department of Epidemiology and Health Statistics, School of Public Health, Guangdong Medical University, No. 1 Xincheng Road, Dongguan, Guangdong 523808, P.R. China

E-mail:hzg@gdmu.edu.cn

"Contributed equally

Key words: Triosephosphate isomerase, gastric cancer, microarray, downstream genes, cell division cycle associated 5 related with $\mathrm{GC}$ development and might be potential new targets in GC treatment.

\section{Introduction}

Gastric cancer (GC) is the fourth most common cancer and the second leading cause of cancer death worldwide and its incidence is the highest in some Asian countries such as China and Japan $(1,2)$. New molecular biomarkers and therapeutic target need to be found to improve the survival rate of GC patients.

Triosephosphate isomerase (TPI) is a housekeeping gene located in $12 \mathrm{p} 13$, encoding the enzyme triosephosphate isomerase. TPI main function is to catalyze the interconversion of dihydroxyacetone phosphate and glyceraldehyde-3-phosphate in the glycolysis pathway and other metabolic pathways (3). TPI is upregulated in many types of cancer, such as esophageal (4), lung (5) and prostate cancer (6). Linge et al (7) found that TPI expression in uveal melanoma tissue of patients who have subsequently developed metastasis was higher than those who have not, while its silencing was associated with a decreased invasion and metastasis. Therefore, the study by Linge et al (7) indicated that TPI may play an important role in the development of tumor associated with migration and invasion. However, TPI involvement in GC needs to be confirmed to establish if it has a crucial role in its development. In the present study, we focused on TPI function in GC cells and on the identification of its downstream functional genes, to provide experimental evidence clarifying its role in this tumor type, with the aim of identifying a new potential target in $\mathrm{GC}$ treatment.

\section{Materials and methods}

Patients and tissue samples. Paraffin-embedded tissue samples were obtained from patients with histological diagnosed GC at Handan Central Hospital during the period between July 2014 and December 2014. Forty-two male and eight female patients, the mean age was 63 years (range, 38-76 years). Patients were classified in TNM stages from I to IV based on the Seven Edition of American Joint Committee on Cancer (AJCC). Informed consent was obtained from the involving 
Table I. siRNA sequences of TPI and CDCA5.

\begin{tabular}{lcc}
\hline siRNA identifer & SenseSeq & AntiSeq \\
\hline TPI & CACCCAUGUGAGGGAAUAATT & UUAUUCCCUCACAUGGGUGTT \\
TPI & AGAGCACCCGUAUCAUUUATT & UAAAUGAUACGGGUGCUCUTT \\
TPI & AGGUCGUCCUGGCCUAUGATT & UCAUAGGCCAGGACGACCUTT \\
TPI & CUAUAAUGGUUGGAACUAATT & UUAGUUCCAACCAUUAUAGTT \\
CDCA5 & CGGAAAGUUUCCUCGCGUATT & UACGCGAGGAAACUUUCCGTT \\
CDCA5 & GGAACUAAAUUUAAGGAAATT & UUUCCUUAAAUUUAGUUCCTT \\
CDCA5 & GAAAGCCCAUCGUCUUAAATT & UUUAAGACGAUGGGCUUUCTT \\
CDCA5 & CCGAGAAACAGAAACGUAATT & UUACGUUUCUGUUUCUCGGTT
\end{tabular}

Table II. Primers for cloning promoters.

\begin{tabular}{lll}
\hline Genes & \multicolumn{1}{c}{ Forward primers } & \multicolumn{1}{c}{ Reverse primer } \\
\hline TPI & GGACTCGGAGTAATCGCCTG & TGTTGGGGTGTTGCAGTCTT \\
BMPR2 & GCCTTGTTATTCATTTCCA & TGTTTCTCCTGTCCATTCA \\
CAV2 & GCTCAACTCGCATCTCAA & AGGAACACCGTCAGGAAC \\
CDCA5 & CGTAAGAAGAAGAAAATGCC & ACAGGACAGGAGGGAGAG \\
CD109 & ATTGTCATCAGTGGGGAGT & TGCCAGGAGTCAGAAAGT \\
PRKACA & TAAGGGCAAATGAACGAA & GGAGTAGAGGAAGGAGGGA \\
ROCK2 & GTGGGTTAGTCGGTTGGT & TGGTTTTGCTGTATCTTCATT \\
SETD7 & TCCTCCTCCTCCAAACTC & GTAATCCGTCATCGTCCA \\
$\beta$-actin & GAAAGATGCTGAAGAAATGAA & TAAAATAAATACACAACCCTCCT \\
\hline
\end{tabular}

Data show the sequence of the primer.

participants to allow the collection and use of the samples. All procedures performed in studies were approved by the ethics committee of the Affiliated Hospital of Guangdong Medical University.

Immunohistochemistry. Fifty gastric cancer tissues and forty-nine samples of para-carcinoma tissue were examined TPI expression by streptavidin -perosidase immunohistochemical staining method. Immunohistochemical staining was performed by using a standard immunoperoxidase staining procedure. TPI protein level was evaluated by two pathologists. According to the cancer cell staining intensity, the TPI staining results were classified as follows: 0 , no staining; 1 , weak staining; 2, moderate staining; and 3, strong staining. The positive cancer cells were classified as score $0,<10 \%$; score $1,11-50 \%$ positive cells; score $2,>50 \%$ positive cells. The percentage of positive cells and the staining intensity was added as the final score. Score 0-1 was considered negative expression; score 2-3 was considered positive expression. Score $>4$ was considered strong positive expression $(8,9)$.

Cell lines. Human gastric cancer cell lines BGC-823, SGC-7901, NCI-N87 and MGC-803 were purchased from the Cell Bank of Institute of Life Science, Chinese Academy of Science (Shanghai, China). All cell lines were cultured with RPMI-1640 medium (Gibco-BRL, Grand Island, NY, USA) medium with $10 \%$ fetal calf serum (FCS), in humidified $5 \%$ $\mathrm{CO}_{2}$ at $37^{\circ} \mathrm{C}$.

Plasmids and small interfering RNAs. The pcDNA-encoding TPI and CDCA5 reporter plasmids were purchased fromShanghai GeneChem, Co., Ltd. (Shanghai, China). The mock vector was used as a negative control. Plasmids were extracted by TIANScript cDNA (Tiangen Biotech, Co., Ltd., Beijing, China). The specific siRNAs for TPI and CDCA5 siRNA and were designed respectively and obtained from Shanghai GeneChem. Scramble siRNA was used as a negative control. Cells were seeded in 6-well plates and transfected with siRNAs or DNA plasmids using Lipofectamine 2000 (Invitrogen, Carlsbad, CA, USA). siRNA sequences of TPI and CDCA5 are shown in Table I.

RNA extraction and real-time PCR. Cells were harvested after 24-h transfection and total RNA was extracted by using TRIzol reagent. Then reverse transcription was performed with First Strand cDNA Synthesis kit (Roche Diagnostics, Indianapolis, IN, USA) following its instructions. Real-time quantitative PCR (RT-qPCR) was performed with FastStart Universal SYBR-Green Master (Roche Diagnostics) by PikoReal $^{\mathrm{TM}}$ Real-Time PCR system (Thermo Fisher Scientific, Waltham, MA, USA). Amplification primers are shown in Table II. 
Table III. Expression of triosephosphate isomerase in gastric cancer tissue and para-carcinoma tissue by immunohistochemistry, $\mathrm{n}(\%)$.

TPI cases

\begin{tabular}{|c|c|c|c|c|c|}
\hline Tissue type & $\mathrm{n}$ & Low expression & High expression & $\chi^{2}$ & P-value \\
\hline Cancer tissue & 50 & $9(18 \%)$ & $41(82 \%)$ & 45.3 & $<0.001^{\mathrm{a}}$ \\
\hline Para-carcinoma tissue & 49 & $42(85.7 \%)$ & $7(14.3 \%)$ & & \\
\hline
\end{tabular}

${ }^{\text {aP }}<0.05$ was regarded as statistically significant; TPI, triosephosphate isomerase; $\chi^{2}$, Chi-square test.

Western blot analysis. Total protein was extracted by using RIPA reagent (Beijing Solarbio Science and Technology, Co., Ltd., Beijing, China). Protein samples were fractionated by SDS-PAGE gel (CWBIO, Beijing, China) with concentration of $12 \%$. Then the protein was transferred to PVDF membranes (Immobilon; Millipore, Bedford, MA, USA) and membranes were blocked by skim milk of $5 \%$ concentration for $1.5 \mathrm{~h}$ at room temperature. The membranes were incubated overnight at $4^{\circ} \mathrm{C}$ with primary TPI antibodies $(1: 2,000$; Abcam, Cambridge, MA, USA), CDCA5 antibodies (1:2,000; Abcam), GAPDH antibodies (1:2,000; Abcam), $\beta$-actin (1:2,000; Cell Signaling Technology, Danvers, MA, USA), respectively. Next day, membranes were incubated with secondary antibodies $(1: 2,000 ;$ Abcam) for $1 \mathrm{~h}$ at room temperature. Finally, protein bands were visualized by infrared imaging system (LI-COR Biosciences, Lincoln, NE, USA). Gray values were analysed by the Quantity One software.

Cell proliferation assay. Cells were collected after $24 \mathrm{~h}$ of transfection and cultured in 96-well plates (BGC-823, 30,00/well; MGC-803, 1,000/well). Each group was set to 5-wells. Add $100 \mu \mathrm{l}$ of Cell Counting kit-8 (CCK-8) diluent (10 $\mu \mathrm{l} \mathrm{CCK-8} \mathrm{+}$ $90 \mu$ l RPMI-1640; Dojindo Laboratories, Kumamoto, Japan) and incubated at $37^{\circ} \mathrm{C}$ for $3 \mathrm{~h}$, then optical density (OD) value at $450 \mathrm{~nm}$ was measured by microplate reader (Thermo Fisher Scientific) every $24 \mathrm{~h}$ for 3 days. The experiment was repeated three times.

Colony formation assay. Cells were collected after $24 \mathrm{~h}$ of transfection and cultured in 6- or 12-well plates. Approximately 1-2 weeks later, cells were fixed by precooling methanol for 20 min and stained with $0.2 \%$ crystal at room temperature for $30 \mathrm{~min}$. Colonies containing $>50$ cells were including when counted. This experiment was repeated three times.

Transwell migration assay. Cells were collected after 24-h transfection and suspension was made with RPMI-1640 medium without fetal bovine serum (FBS) (concentration of BGC-823 and MGC-803 cells were $0.5 \times 10^{6}$ and $0.2 \times 10^{6}$ ) added into upper chambers of Transwell ( $8 \mu \mathrm{m}$ for 24 -well plate; BD Biosciences), each well added $200 \mu 1$ suspension. The lower chambers were filled with $600 \mu 1$ RPMI-1640 containing $10 \%$ FBS. Then, the cells were cultured in incubator with $5 \% \mathrm{CO}_{2}$ at $37^{\circ} \mathrm{C}$. After $48 \mathrm{~h}$, cells were fixed, stained and photographed in 5 random fields and counted. The experiment was repeated three times.
Transwell invasion assay. The Matrigel (Corning, Inc., Corning, NY, USA) matrix was diluted with RPMI-1640 medium without FBS (1:5), and filled into upper chambers of Transwell (60 $\mu \mathrm{l} /$ well). Then the plates were placed at $37^{\circ} \mathrm{C}$ for $4 \mathrm{~h}$. After that, $200 \mu \mathrm{l}$ cells suspension was added to upper chambers

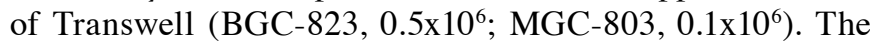
lower chamber was added with $600 \mu \mathrm{l}$ RPMI-1640 medium supplemented with $10 \% \mathrm{FBS}$ in $5 \% \mathrm{CO}_{2}$ at $37^{\circ} \mathrm{C}$. After $48 \mathrm{~h}$ of incubation, the remaining steps were the same as the migration assay.

Flow cytometric cell cycle distribution and apoptosis assay. Cells were harvested after 48 -h transfection, then fixed with pre-cooling $70 \%$ ethanol at $4^{\circ} \mathrm{C}$ for $2 \mathrm{~h}$ or overnight. Then cells were stained with $50 \mathrm{mg} / \mathrm{ml}$ propidium iodide (PI) for $30 \mathrm{~min}$ at room temperature in the dark. Cell cycle analyses were performed by a FACSCalibur flow cytometer (BD Immunocytometry Systems; BD Biosciences, San Jose, CA, USA). The percentage of cells in G1, S and G2 phase was analyzed by the ModFit software.

To detect cell apoptosis, cells were harvested $48 \mathrm{~h}$ after transfection and were measurement with the Annexin V-FITC/PI apoptosis detection kit (Dojindo, Shanghai, China) according to manufacturer's instructions. Cells were incubated with Annexin V-FITC and PI solution in the dark for $15 \mathrm{~min}$. After that, cells were analyzed for apoptosis rates using a FACScan flow cytometer. Each sample analyzed had at least 10,000 cells.

Microarray analysis. TPI downstream genes were detected by microarray analysis, Affymetrix GeneChip Human Genome (Affymetrix, Inc., Santa Clara, CA, USA). Total RNA was extracted from MGC-803 cells with siTPI or siNC transfection. The RNA quality was determined by NanoDrop 2000 (Thermo Fisher Scientific) and Agilent Bioanalyzer 2100 (Agilent Technologies, Santa Clara, CA, USA). Each group was set to three repetitions. Gene Ontology (GO) analysis and KEGG pathway analysis was carried out as previously described (10).

\section{Results}

TPI expression in GC tissues and para-carcinoma tissues. In total, $50 \mathrm{GC}$ samples were analyzed by immunohistochemistry. TPI staining was observed in GC cell cytoplasm and membrane. TPI staining was positive in the cytoplasm. The results showed that TPI expression in GC tissues was markedly 
A

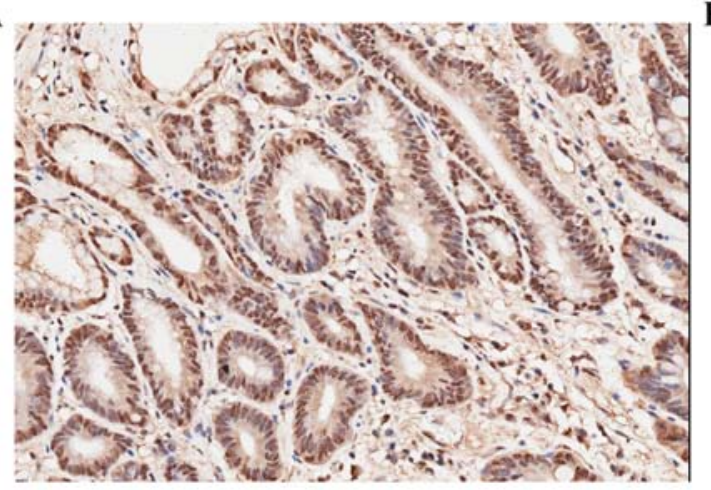

B

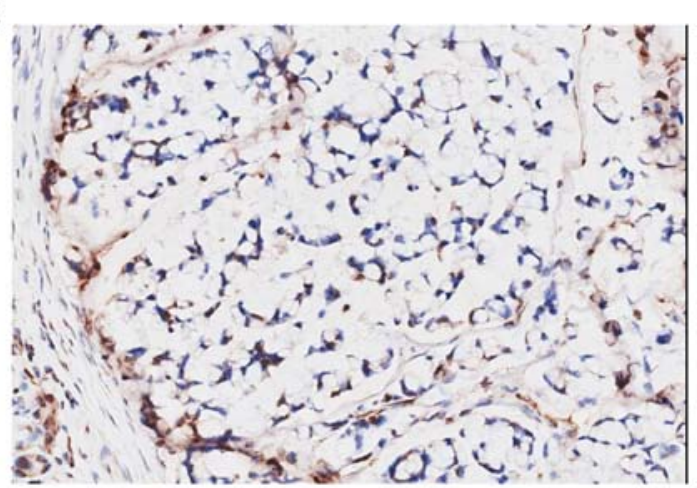

Figure 1. TPI expression in human GC specimens. (A) TPI high intensity staining in GC specimens. (B) TPI negative immunoreactivity in GC specimens.

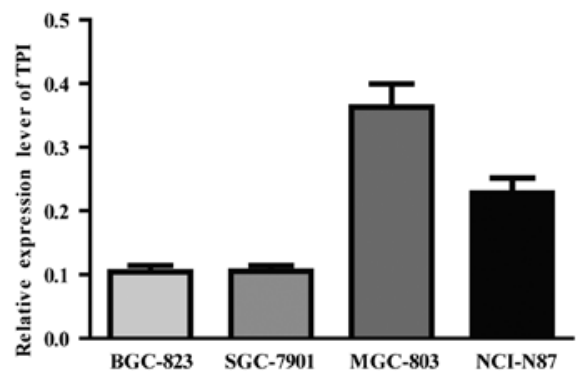

Figure 2. TPI mRNA measured by RT-qPCR in four GC cell lines. Data are expressed as mean $\pm \mathrm{SD}$.

higher than in para-carcinoma tissues $(\mathrm{P}<0.001)$ (Table III): $41 / 50$ specimens $(82 \%)$ showed a highly intensity staining (score $\geq 2$ ) (Fig. 1A), and 9/50 specimens (18\%) showed negative staining (score 0-1) (Fig. 1B). We also examined the relationship between TPI expression and patients' characteristics or clinicopathological characteristics. However, no statistical differences were found between TPI expression and age, sex and tumor grade (Table IV).

TPI mRNA expressions in human gastric cancer cell lines. TPI expression was detected in four GC cell lines by RT-qPCR. TPI highest mRNA expression was observed in MGC-803 cell line and relatively low TPI mRNA expression was found in BGC-823 and SGC-7901 cell lines (Fig. 2). Therefore, BGC-823 cell line was chosen to perform TPI overexpression by plasmid transfection and MGC-803 to perform TPI knockdown by siRNA.

TPI upregulation effect on proliferation, colony formation, migration and invasion and cell cycle distribution in BGC-823 cells. Since TPI is upregulated in many carcinomas, we investigated the role of TPI in gastric cancer cell line behavior. Since TPI expression was low in BGC-823, we chose this cell line to explore the effect of TPI overexpression by pcDNA3.1 (+)/TPI transfection. RT-qPCR and western blot results demonstrated that TPI mRNA and protein expression were significantly higher in cells transfected with pcDNA3.1 (+)/TPI than in cells transfected with empty vector pcDNA3.1 (Fig. 3A and B; $\mathrm{P}<0.001)$. The upregulated TPI group was named BGC-TPI and the control group was named BGC-NC.
Table IV. Relationship between TPI and clinicopathological characteristics in GC.

\begin{tabular}{lrccc}
\hline $\begin{array}{l}\text { Variables } \\
\text { P-value }\end{array}$ & \multicolumn{1}{c}{$\mathrm{n}$} & Negative & Positive & \\
\hline Age (years) & & & & $>0.05$ \\
$<60$ & 14 & 3 & 11 & \\
$\geq 60$ & 36 & 6 & 30 & \\
Sex & & & & $>0.05$ \\
Male & 42 & 8 & 34 & \\
Female & 8 & 1 & 7 & \\
T stage & & & & $>0.05$ \\
T1-2 & 3 & 1 & 2 & \\
T3-4 & 47 & 8 & 39 & \\
N stage & & & & $>0.05$ \\
N0 & 11 & 1 & 10 & \\
N1-3 & 39 & 8 & 31 & $>0.05$ \\
M stage & & & & \\
M0 & 46 & 8 & 38 & \\
M1 & 4 & 1 & 3 & \\
TNM stage & & & & \\
I-II & 3 & 1 & 29.05 \\
III-IV & 47 & 8 & 29 & \\
\hline
\end{tabular}

Statistical analyses were carried out by Pearson's $\chi^{2}$-test. $\mathrm{P}<0.05$ was considered statistically significant. TPI, triosephosphate isomerase; $\mathrm{GC}$, gastric cancer.

In order to evaluate the role of TPI in GC progression, we used CCK-8 test and colony formation assay to detect cell proliferative ability, Transwell assay to detect migration and invasion abilities, and flow cytometry to detect cell cycle distribution in BGC-823 cells. The results showed that proliferation and colony formation abilities were significantly increased in the TPI upregulated group than in the control group (Fig. 3C and D; $\mathrm{P}<0.001)$. Transwell assay results indicated that BGC-823 migration rate was higher in the TPI upregulated group than in the control group (Fig. 4A; $\mathrm{P}<0.001$ ). The transwell invasion assay results indicated that TPI increased expression caused a 
A

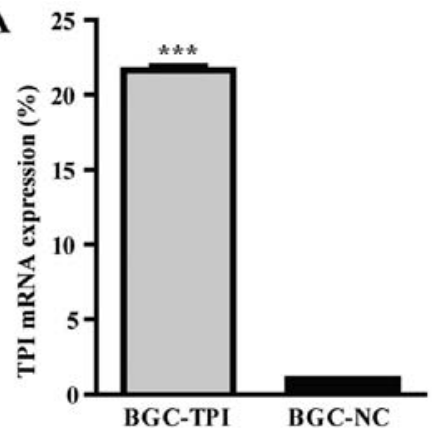

D

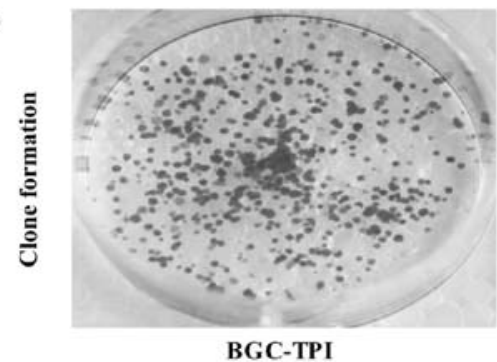

B

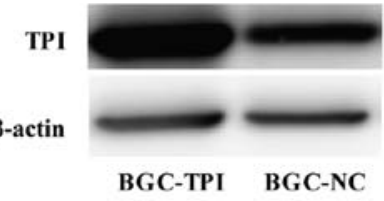

C

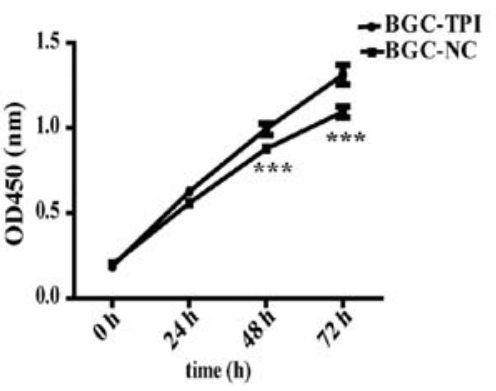

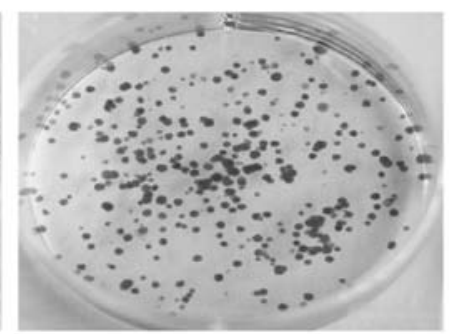

BGC-NC

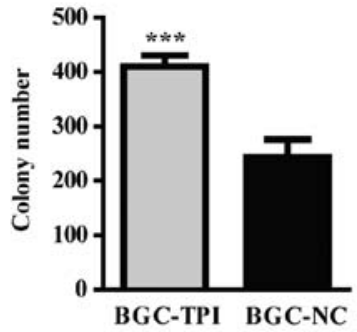

Figure 3. Effect of TPI overexpression on proliferation in BGC-823 cells. BGC-TPI, transfected with pcDNA-3.1/TPI; BGC-NC, empty vector pcDNA3.1. (A) TPI mRNA was 20 times increased in BGC-TPI group than in BGC-NC group $\left({ }^{* * *} \mathrm{P}<0.001\right)$. Data were expressed as mean \pm SD. (B) The result of western blot analysis showed that TPI protein was increased in BGC-TPI group compared to BGC-NC group. (C) TPI overexpression resulted in an increased cell growth compared with BGC-NC group $\left({ }^{* * *} \mathrm{P}<0.001\right)$. (D) The result of colony formation assay showed that BGC-TPI group colony numbers were higher than in BGC-NC group $(* * * 2<0.001)$. Data were expressed as mean \pm SD.

A

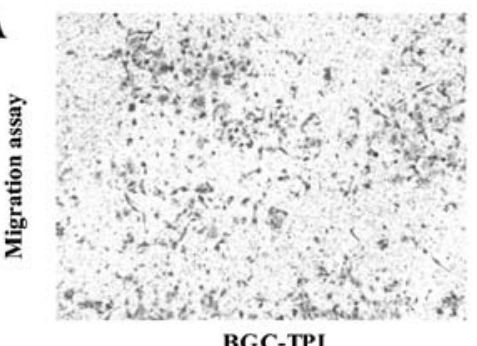

B

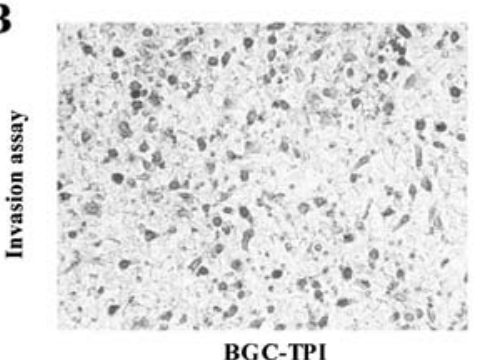

C

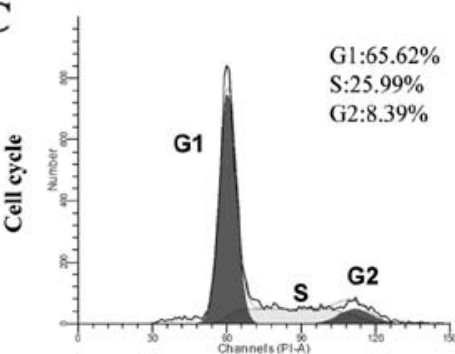

BGC-TPI

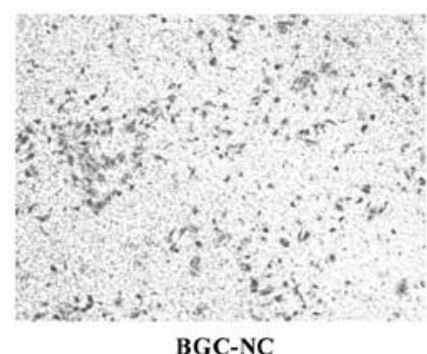

BGC-NC

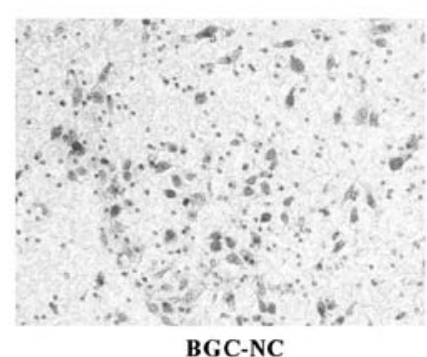

BGC-NC

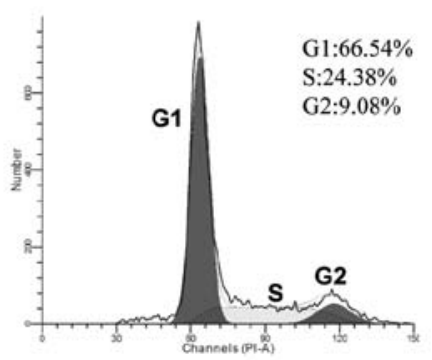

BGC-NC
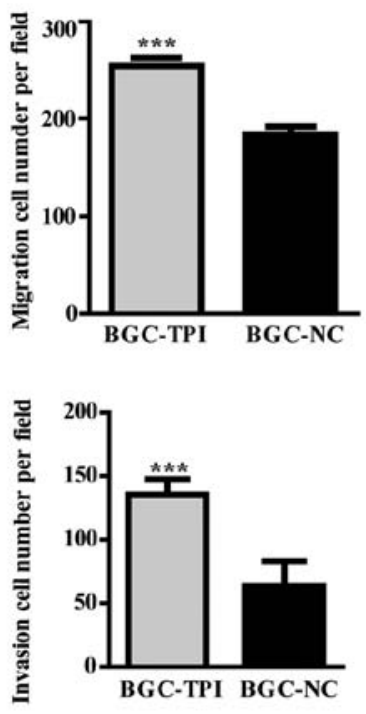

Figure 4. Effects of TPI overexpression on Transwell migration, Transwell invasion and cell cycle distribution in BGC-823 cells. (A) Transwell migration assay showed that BGC-TPI group cell migration was higher than in BGC-NC group $\left.{ }^{* * * *} \mathrm{P}<0.001\right)$. Data were expressed as mean $\pm \mathrm{SD}$. (B) Transwell invasion assay showed that BGC-TPI group cell invasion was higher than in BGC-NC group $\left({ }^{* * *} \mathrm{P}<0.001\right)$. Data were expressed as mean \pm SD. (C) Cell cycle distribution measured by flow cytometry. TPI overexpression did not significantly affect the cell cycle. Each phase of the cell cycle did not change in BGC-TPI and BGC-NC group after 48 -h transfection. Data were expressed as mean $\pm \mathrm{SD}$. ${ }^{* * * *} \mathrm{P}<0.001$. 


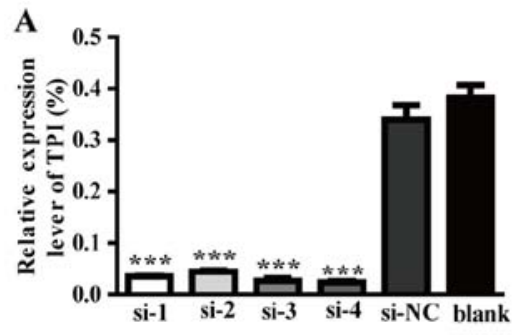

D

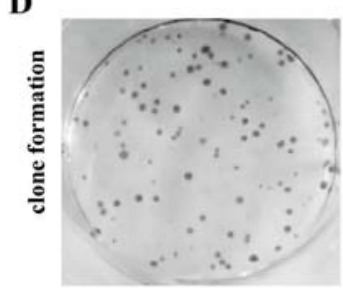

si-3
B

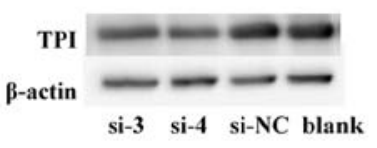

C

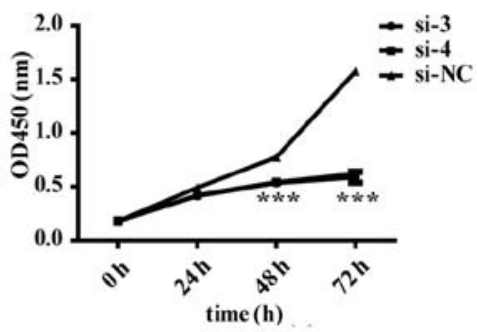

Figure 5. Effect of TPI silencing on proliferation in MGC-803 cells. Four TPI-specific siRNAs (siTPI-1, siTPI-2, siTPI-3 and siTPI-4) were abbreviated as si-1, si-2, si-3 and si-4, respectively. The control group was transfected by scramble siRNA and named as si-NC. (A) Cells transfected with siTPI showed a reduced TPI mRNA expression compared to cells transfected with scramble siRNA ( $\left.{ }^{* * *} \mathrm{P}<0.001\right)$. Data were expressed as mean \pm SD. (B) Western blot result showed that TPI protein in si-NC group was higher than that in si-3 and si-4 groups after 48-h transfection in MGC-803 cells. (C) CCK-8 assay showed that TPI silencing resulted in a decreased cell growth compared with si-NC group $\left({ }^{* * *} \mathrm{P}<0.001\right)$. (D) Colony number in siTPI group was less than in siNC group $\left({ }^{* * *} \mathrm{P}<0.001\right)$. Data were expressed as mean $\pm \mathrm{SD}$.

Table V. Differentially expressed genes in Gene Ontology (GO) categories.

\begin{tabular}{|c|c|c|c|c|c|}
\hline Diseases or function annotation & P-value & $\begin{array}{l}\text { Predicted } \\
\text { activation } \\
\text { state }\end{array}$ & $\begin{array}{l}\text { Activation } \\
\text { z-score }\end{array}$ & Molecules & DEGs \\
\hline Autophagy & 0.000175 & Decreased & -3.933 & 41 & ROCK2 \\
\hline Proliferation of cells & $1.08 \mathrm{E}-13$ & Decreased & -3.568 & 319 & $\begin{array}{l}\text { CDCA5, BMPR2, CAV2, CD109, } \\
\text { PRKACA, ROCK2, TFAM }\end{array}$ \\
\hline Cell viability of cell lines & 0.0000909 & Decreased & -3.165 & 25 & \\
\hline Migration of cells & $3.76 \mathrm{E}-09$ & Decreased & -2.585 & 174 & CDCA5, BMPR2, PRKACA, ROCK2 \\
\hline Cell movement & 6.04E-09 & Decreased & -2.429 & 189 & BMPR2, PRKACA, ROCK2 \\
\hline Cell proliferation of tumor cell lines & $2.18 \mathrm{E}-13$ & Decreased & -2.414 & 163 & BMPR2, PRKACA \\
\hline Cell death of cancer cells & 0.000458 & Increased & 2.434 & 37 & \\
\hline Necrosis & $2.13 \mathrm{E}-11$ & Increased & 2.541 & 235 & PRKACA, ROCK2, TFAM \\
\hline Cell death & $3.77 \mathrm{E}-12$ & Increased & 2.812 & 291 & PRKACA, ROCK2, TFAM \\
\hline Organismal death & 2.12E-08 & Increased & 5.064 & 204 & BMPR2, PRKACA, TFAM \\
\hline Morbidity or mortality & $2.42 \mathrm{E}-08$ & Increased & 5.21 & 206 & BMPR2, PRKACA, TFAM \\
\hline
\end{tabular}

DEGs, differentially expressed genes.

significant increase in BGC-823 invasive ability compared to control group (Fig. 4B; $\mathrm{P}<0.001$ ). Cell cycle distribution results showed no significant difference between BGC-823 upregulated group and control group (Fig. 4C).

TPI knockdown effect on proliferation, colony formation, migration and invasion, cell cycle distribution and apoptotic abilities in MGC-803 cells. Since we demonstrated that TPI overexpression has a role in increasing proliferation, migration and invasion, TPI was silenced in MGC-803 cells by siRNA to evaluate the TPI role in GC development and progression. The results demonstrated that TPI mRNA and protein expression were significantly lower in cells transfected with TPI siRNA than in cells transfected with negative siRNA (Fig. 5A and B). TPI mRNA level was significantly reduced by $90 \%$ in comparison to the si-NC group (Fig. 5A; P<0.001). TPI protein level was also significantly reduced by $55.3 \%$ in comparison to the si-NC group (Fig. 5B). In order to obtain more reliable results, TPI siRNA-3 and TPI siRNA-4 were chosen for our further experiments.

The results indicated that TPI silencing could decrease proliferation and colony formation abilities in the si-3 and 
A
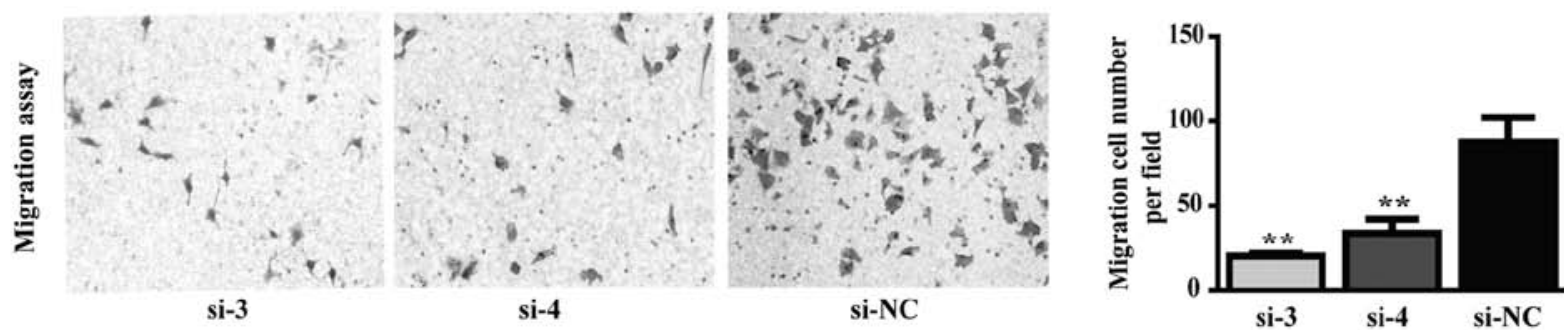

B
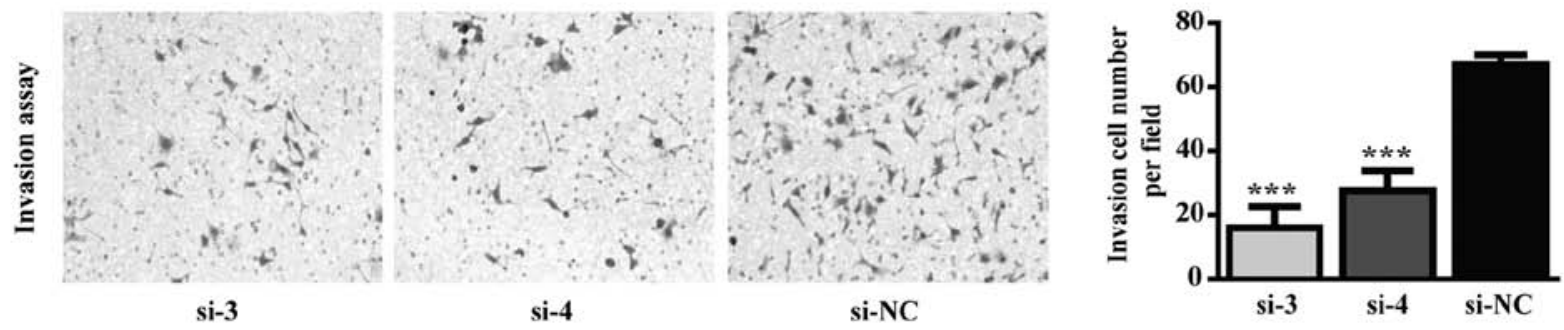

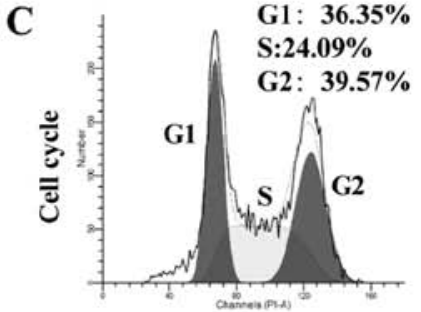

si-3

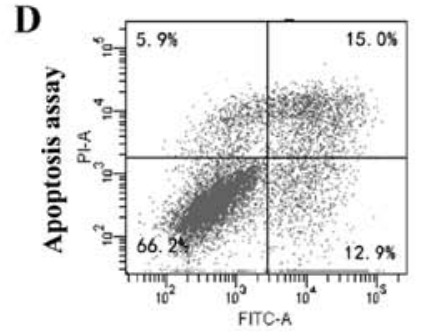

si-3

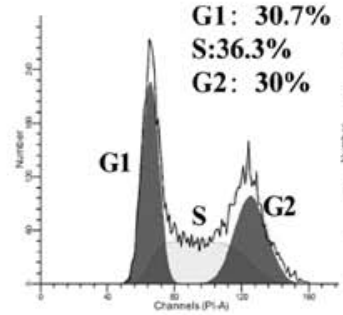

si-4

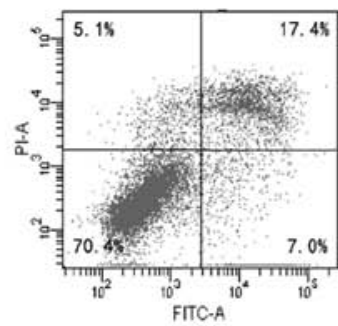

si-4

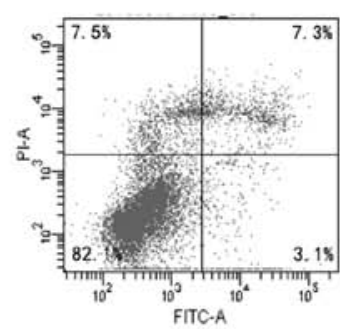

si-NC
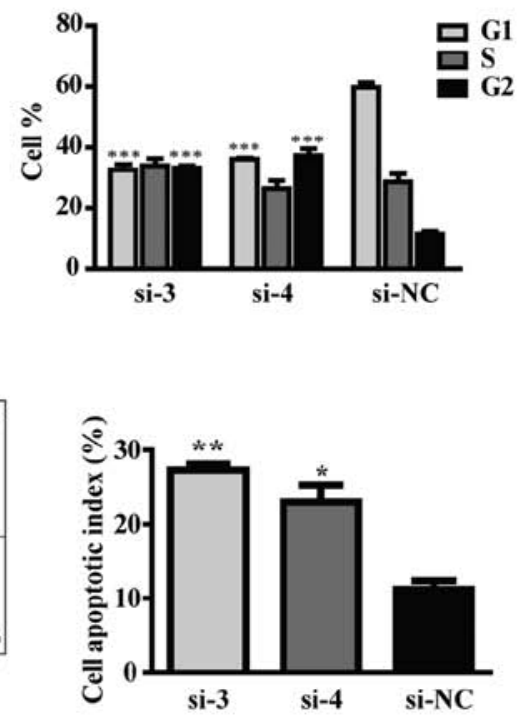

Figure 6. Effects of TPI silencing on Transwell migration, Transwell invasion, apoptosis and cell cycle distribution in MGC-803 cells. (A) Migrated cells in the siTPI group showed significantly lower motility compared to that in siNC group $(\mathrm{P}<0.01)$. Data were expressed as mean $\pm \mathrm{SD}$. (B) Invading cells in the siTPI group showed significantly lower motility compared to that in siNC group $(\mathrm{P}<0.001)$. Data were expressed as mean $\pm \mathrm{SD}$. (C) The result of cell cycle distribution showed that the amount of cells in $\mathrm{G} 2 / \mathrm{M}$ phase was increased in si-3 and si-4 groups compared to control group siNC ( $<<0.001$ ), while the amount of cells in G1 phase was decreased in si-3 and si-4 groups compared to control group siNC (P<0.001). Data were expressed as mean \pm SD. (D) TPI silencing in MGC-803 cells resulted in a remarkable increase in apoptosis compared to control group $(\mathrm{P}<0.05)$. Data were expressed as mean $\pm \mathrm{SD}$. $\mathrm{P}<0.05$; ${ }^{* *} \mathrm{P}<0.01$; ${ }^{* * * *} \mathrm{P}<0.001$.

si-4 knockdown groups (Fig. 5C and D). In addition, TPI silencing inhibited tumor cell migration and invasion abilities in MGC-803 cells (Fig. 6A and B). Cell cycle distribution results showed a dramatic increase in the G2-M fraction, from $<10 \%$ in control group to $>30 \%$ in TPI si-3 and TPI si- 4 groups, while a significant decrease in the G1 fraction was observed (Fig. 6C; $\mathrm{P}<0.001$ ). Flow cytometric results showed that apoptotic cells in the knockdown group measured by Annexin V-FITC were significantly increased compared to control group (Fig. 6D; $\mathrm{P}<0.05$ ). These results indicated that the anti-proliferative effect of siTPI was due to cell cycle arrest in $\mathrm{G} 2$ phase and consequent apoptosis promotion.

TPI downstream genes by GeneChip. According to the $\mathrm{P}<0.05$ cut-off criteria and $\log 2$ fold changel $\geq 1$, a total of
948 differentially expressed genes (DEGs) were obtained, including 746 downregulated and 202 upregulated DEGs. The heat map of hierarchical clustering analysis showed a clear DEGs different expression between TPI knockdown and negative controls and the majority of DEGs were downregulated (Fig. 7A).

TPI downstream genes screening and verification. GO analysis showed that TPI knockdown could decrease autophagy, viability, proliferation, cell migration, and increase cell death, necrosis, organismal death and morbidity or mortality (Table V). Most of our experiment results were consistent with these function predictions. Our experiment showed that TPI silencing could inhibit proliferation, migration and invasion of MGC-803 cells. Downstream 
A
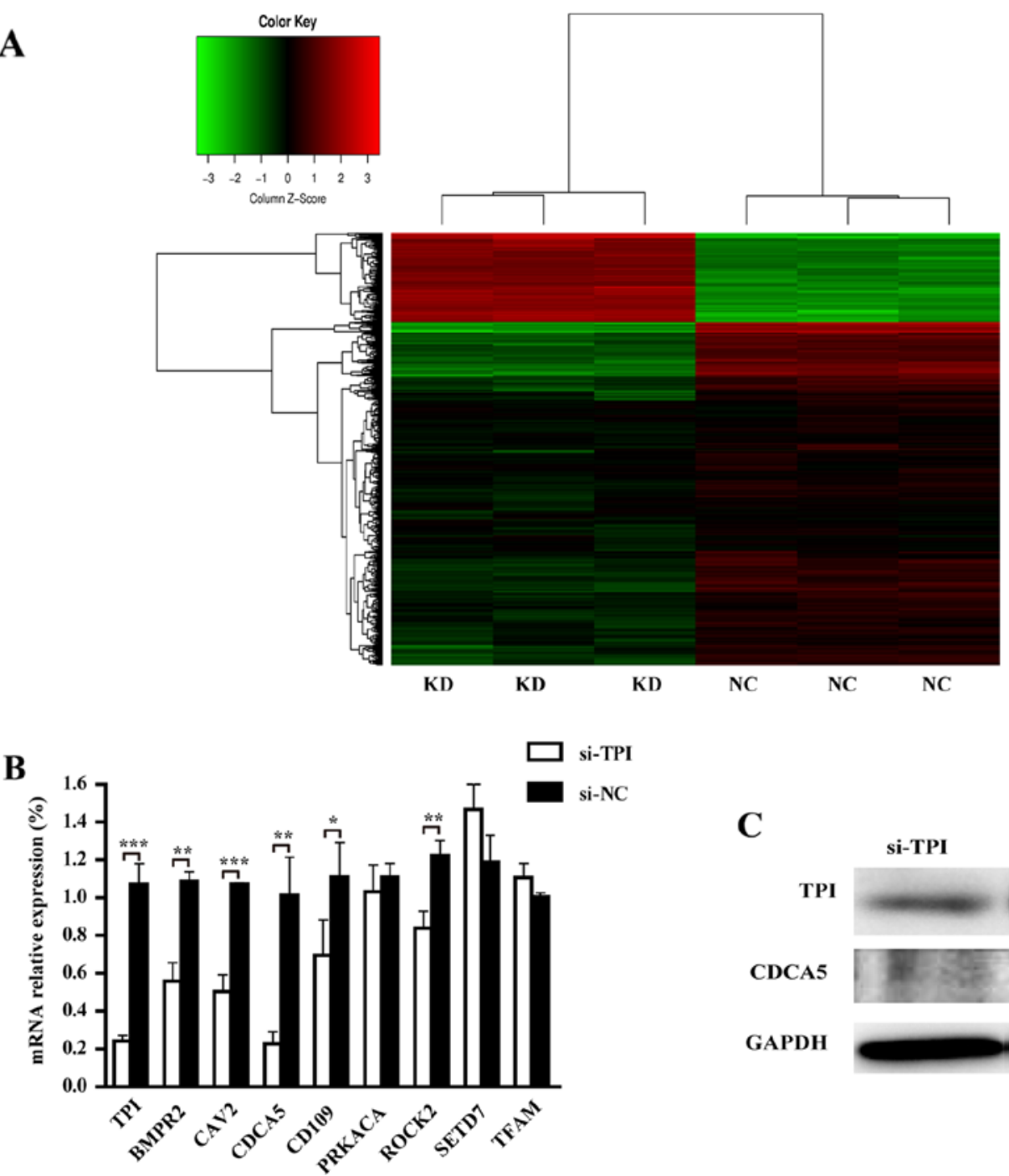

C

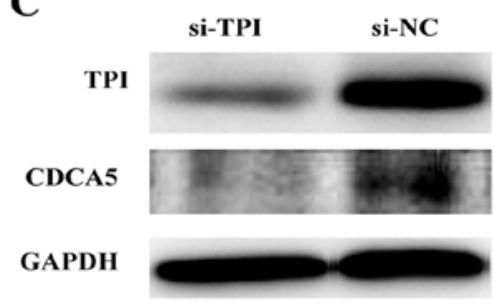

Figure 7. TPI downstream gene screening and verification. (A) DEGs hierarchical clustering. Three replicates per group are shown. KD, knockdown; NC, negative control. Red color indicates upregulated DEGs; green color indicates downregulated DEGs. (B) RT-qPCR was used to verify GeneChip results. Eight genes were selected for verification. The result showed that BMPR2, CAV2, CDCA5, CD109 and ROCK2 mRNA were significantly decreased when TPI was silenced by siRNA. Data were expressed as mean \pm SD. (C) CDCA5 protein level was analyzed by western blot analysis after TPI knockdown. The result showed that CDCA5 protein was decreased in si-TPI group compared to si-NC group. ${ }^{*} \mathrm{P}<0.05 ;{ }^{* *} \mathrm{P}<0.01 ;{ }^{* * *} \mathrm{P}<0.001$.

genes were analyzed according to the function predicted by GO analysis. Within the functional categories, downregulated genes were selected by literature search in the database. Among the downregulated genes, several genes were related with proliferation, migration and invasion such as CDCA5, BMPR2, CAV2, CD109, PRKACA, ROCK2, TFAM and PRKACA. Thus, these genes were selected to validate their expression by RT-qPCR. TPI knockdown resulted in CDCA5, BMPR2, CAV2, CD109 and ROCK2 mRNA downregulation (Fig. 7B; P<0.05). Since CDCA5 mRNA showed the most remarkable decrease, we verified whether it was regulated by TPI at protein level. The result of western blot analysis indicated that CDCA5 protein was decreased when TPI was silenced (Fig. 7C). Thus, CDCA5 was chosen for our next experiment.

Effect of CDCA5 knockdown on MGC-803 cell proliferation, colony formation, migration and cell cycle distribution. Four CDCA5-specific siRNAs (siRNA-1, siRNA-2, siRNA-3 and
siRNA-4) were transfected into MGC-803 cells. The control group was transfected with scrambled siRNA and named si-NC. RT-qPCR and western blot analysis were used to detect the efficiency of CDCA5 knockdown. CDCA5 mRNA and protein were reduced after siRNA transfection (Fig. 8A and B). Functional results indicated that CDCA5 knockdown could inhibit MGC-803 cells proliferation, colony formation and migration compared to control group (Fig. 8C-E; $\mathrm{P}<0.01$ ). Moreover, CDCA5 knockdown could arrest cell cycle in $\mathrm{G} 2 / \mathrm{M}$ phase (Fig. 8F; $\mathrm{P}<0.01$ ).

Effect of CDCA5 overexpression on MGC-803 cell proliferation, colony formation and migration abilities. The eukaryotic expression vector of CDCA5 was constructed and was transfected to MGC-803 cells. The empty vector was as control group. The result of RT-qPCR and western blot analysis showed that the mRNA and protein level of CDCA5 were increased in CDCA5 overexpression group (Fig. 9A and B). CDCA5 overexpression could enhance growth and promote 

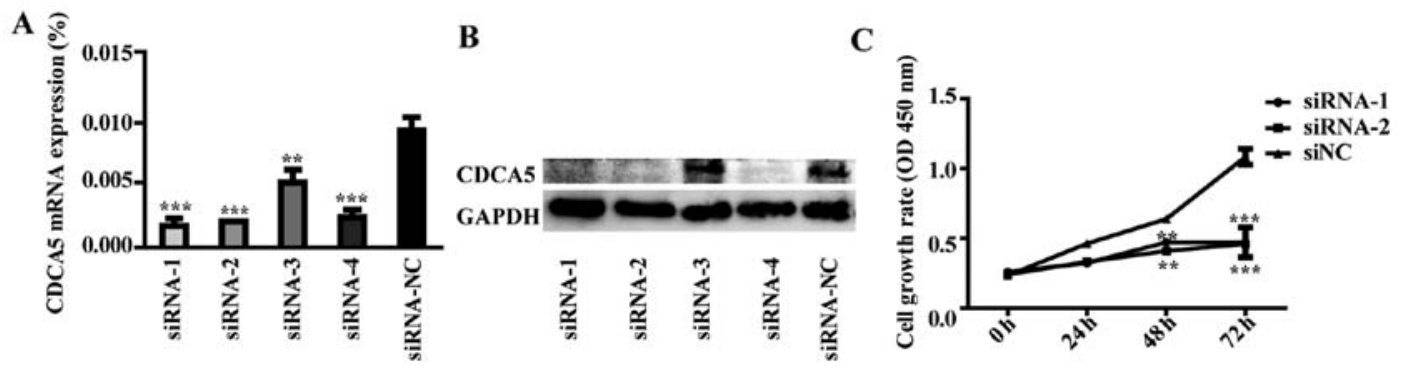

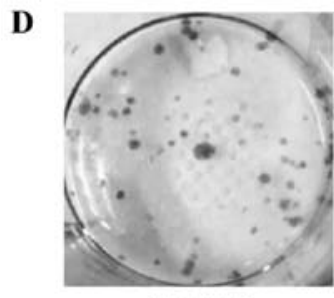

CDCA5-sil

E

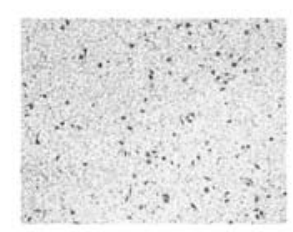

CDCA5-sil

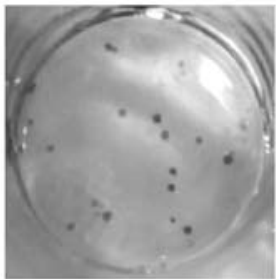

CDCA5-si2

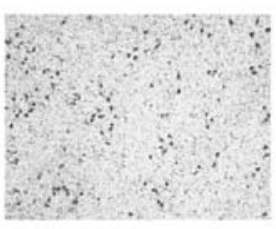

CDCA5-si2

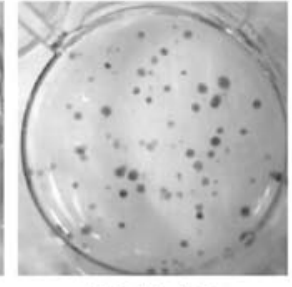

CDCA5-siNC

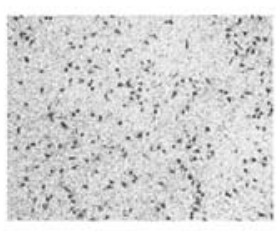

CDCA5-siNC
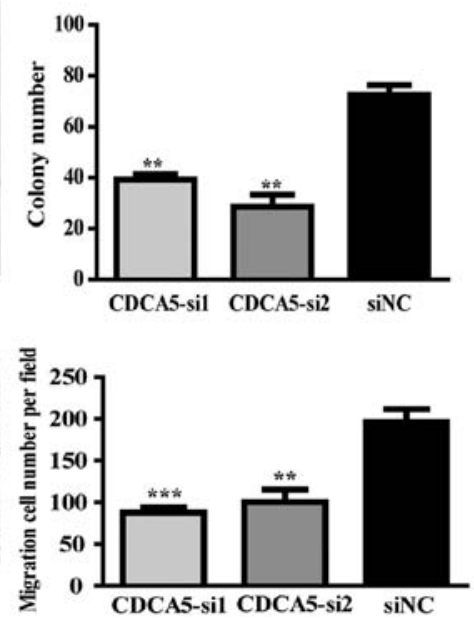

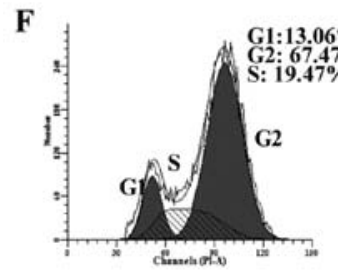

CDCA5-sil

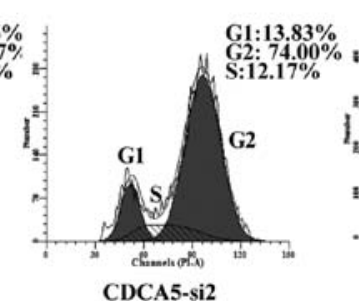

CDCA5-si2

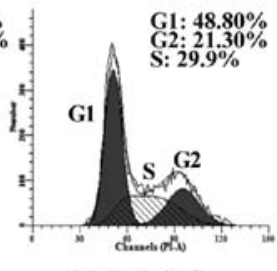

CDCA5-siNC

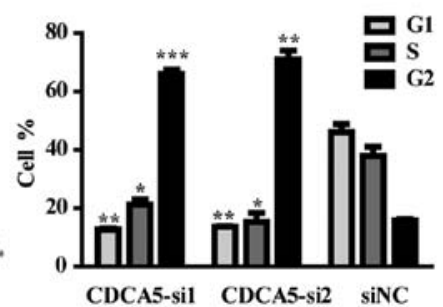

CDCA5-sil CDCA5-si2 siNC

Figure 8. Effects of CDCA5 knockdown on MGC-803 cells. (A) Cells transfected with siCDCA5 showed a reduced CDCA5 mRNA expression compared to cells transfected with scramble siRNA $(\mathrm{P}<0.01)$. Data were expressed as mean $\pm \mathrm{SD}$. (B) The result of western blot analysis showed that siRNA1, siRNA2 and siRNA4 groups resulted in a decreased CDCA5 protein compared to siNC group. (C) Cell growth curves showed that CDCA5 knockdown significantly inhibited MGC-803 cells growth $(\mathrm{P}<0.01)$. (D) Clone formation rate was lower after CDCA5 knockdown compared to control group (P<0.01). Data were expressed as mean \pm SD. (E) Transwell migration assay showed that CDCA5 knockdown could suppress MGC-803 cell migration (P<0.01). Data were expressed as mean \pm SD. $(F)$ The result of cell cycle distribution showed that CDCA5 knockdown resulted in a decreased number of cells in G1 phase and S phase, while resulted increased in $\mathrm{G} 2 / \mathrm{M}$ phase compared to control group $(\mathrm{P}<0.05)$. Data are expressed as mean $\pm \mathrm{SD}$. ${ }^{*} \mathrm{P}<0.05 ;{ }^{* * *} \mathrm{P}<0.01 ;{ }^{* * * *} \mathrm{P}<0.001$.

colony formation of MGC-803 cells (Fig. 9C and D; P<0.01). Furthermore, CDCA5 overexpression could also enhance MGC-803 cell migration (Fig. 9E; $\mathrm{P}<0.001$ ).

\section{Discussion}

In the present study, we found that TPI expression was upregulated in GC tissues compared to matched para-carcinoma tissue. These results suggested that TPI might have oncogenic functions in GC. In recent years, TPI was reported overexpressed in several tumors, including pancreatic (11), esophageal (4), colorectal cancer (12) and lung squamous cell carcinoma (5). However, none of these previous studies reported the relationship between TPI expression and patients' characteristics or clinicopathological characteristics although we did not find any statistical difference between them, probably due to the small sample size in this study. The results of the present study showed that TPI was overexpressed in GC tissues, which was consistent with the previous reports.
TPI upregulation could significantly increase the proliferation and colony formation in BGC-823 cells, while silencing inhibited these abilities in MGC-803 cells. Similar results have been reported by the study of Ritterson Lew and Tolan (13) who showed that TPI knockdown by siRNA in Ras-transformed NIH-3T3 cells could decrease cancer cell proliferation by $25 \%$ because glycolysis pathway was affected in some ways. Tumor cells proliferating more quickly could accelerate the tumor growth and the development. The ability of colony formation in cancer cells reflected the proliferation of tumor cells and ability of tumor formation to a certain extent, suggesting that the enhanced ability of colony formation could increase the formation of metastatic tumors. The present study indicated that TPI promoted tumor growth.

In addition, invasion and metastasis were analyzed to further explore the function of TPI in GC cells. Our results indicated that invasion and metastatic abilities were increased when TPI was overexpressed in BGC-823, while they were reduced when it was silenced in 
A

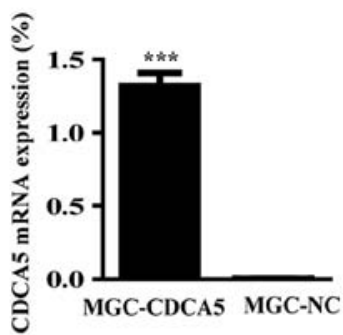

D

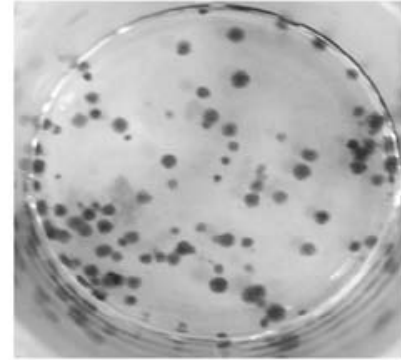

MGC-CDCA5

E

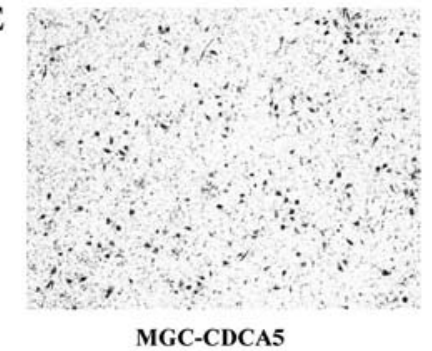

B
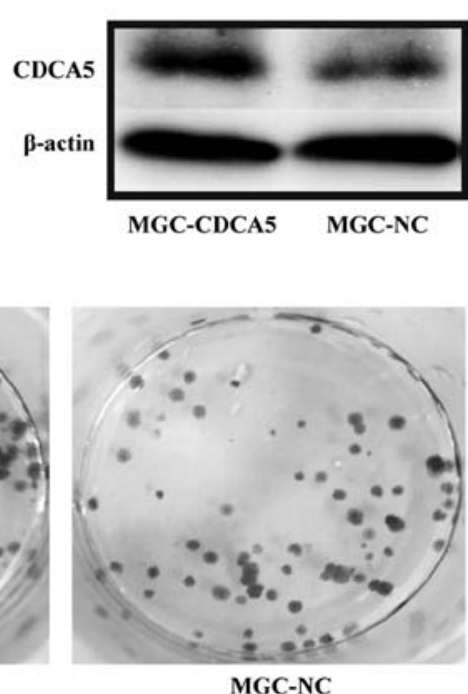

MGC-NC

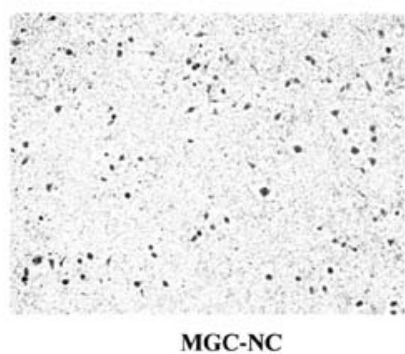

C
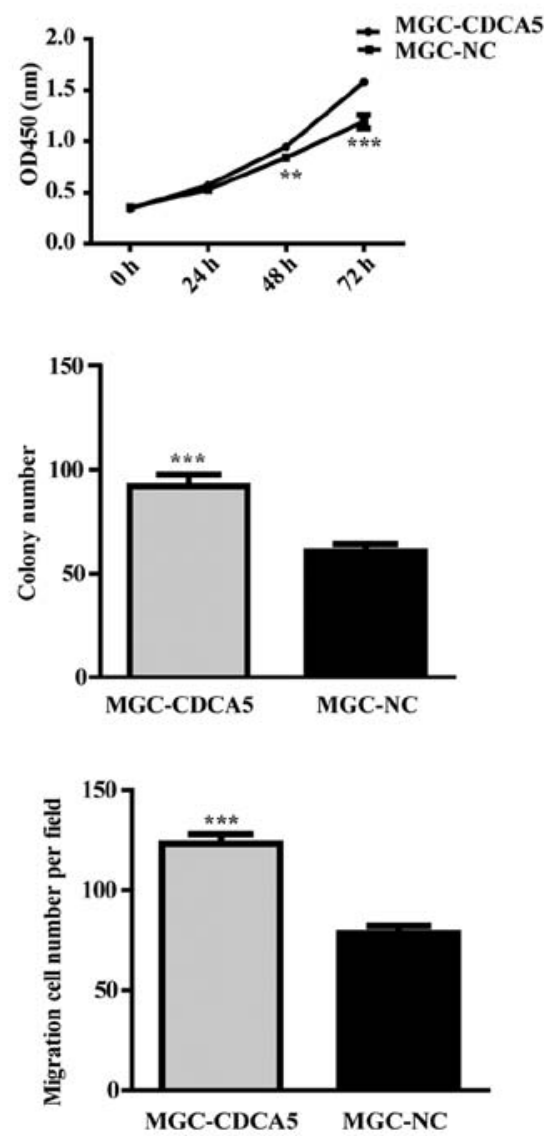

Figure 9. Effect of CDCA5 overexpression on MGC-803 cells. MGC-CDCA5, CDCA5 overexpression; MGC-NC, control group. (A) CDCA5 mRNA was increased in MGC-CDCDA5 group compared to MGC-NC group $(\mathrm{P}<0.001)$. Data are expressed as mean \pm SD. (B) The result of western blot showed that CDCA5 protein increased in MGC-CDCDA5 group compared to MGC-NC group. (C) Cell growth curves showed a faster cell growth rate in MGCCDCA5 group compared to MGC-NC group after 48-h transfection ( $\mathrm{P}<0.01)$. (D) Colony number in MGC-CDCA5 group was higher than in MGC-NC group $(\mathrm{P}<0.001)$. Data are expressed as mean $\pm \mathrm{SD}$. (E) Transwell migration assay showed that cell migration number was higher in MGC-CDCA5 group than in MGC-NC group $(\mathrm{P}<0.001)$. Data are expressed as mean $\pm \mathrm{SD} .{ }^{*} \mathrm{P}<0.05 ;{ }^{* *} \mathrm{P}<0.01 ;{ }^{* * *} \mathrm{P}<0.001$.

MGC-803. Thongwatchara et al (14) reported that TPI expression is elevated in patients with positive lymphatic metastasis compared to patients without lymphatic metastasis. Moreover, two studies showed that TPI expression is also higher in cells with highly metastatic ability than in cells with poor metastatic ability $(15,16)$. Thus, our result suggested that TPI might play a crucial role in cell invasion and metastatic abilities in GC cells. TPI is an enzyme required in glycolysis. In order to meet the need of local hypoxia in rapid growth of tumor cells, most of them obtain energy through aerobic glycolysis and this phenomenon is called the Warburg effect (17). This means that TPI is indispensable in Warburg effect. The Warburg effect plays an important role in tumor metastasis and may be the reason for the invasion and metastasis of tumor (18). Notably, one of the reasons inducing cancer cell movement to other region is because the end-product of glycolysis, lactic acid, makes the microenvironment acid, leading to an uncomfortable tumor cells life (19). The above studies give some evidence explaining the TPI ability of promoting invasion and metastasis in cancer cells.

The present study showed that TPI overexpression or knockdown could affect the malignant biological behavior of
GC cell lines, but little is known about its molecular mechanism. For example, it is not known which downstream genes are directly or indirectly regulated by TPI and which downstream genes have a biological function similar with TPI. In order to evaluate these unknown aspects, TPI downstream genes after TPI knockdown were analyzed. The function predicted by GO analysis showed that TPI knockdown could decrease cell proliferation and migration, which were consistent with our experimental results. Furthermore, the expression of several genes was decreased when TPI was silenced, including CDCA5, CAV2, BMPR2, CD109 and ROCK2, suggesting that they might be regulated by TPI. Among these genes, CDCA5 showed the most decreased expression.

The main function of CDCA5 is to ensure that the sister chromatids are accurately separated at the later stage of mitosis (20). In recent years, CDCA5 was reported overexpressed in a number of cancer tissues such as lung cancer tissue, squamous cell carcinoma (OSCC) tissue, urothelial carcinoma tissue and was related with the prognosis in patients. Indeed, high CDCA5 expression was associated with a poor prognosis (21-23). These results suggested that CDCA5 may have oncogenic functions like TPI. On the one hand, our present study showed that CDCA5 overexpression 
could accelerate the growth of MGC-803 cells, and promote cell migration ability. These results demonstrated for the first time that CDCA5 overexpression could increase the malignant behavior of GC cells. Moreover, the present results might give some evidence explaining CDCA5 overexpression in cancer cells and why high CDCA5 expression was associated with a poor prognosis. On the other hand, this study showed that CDCA5 knockdown could suppress proliferation, migration and invasion abilities of MGC-803 cell and could arrest the cell cycle in G2/M phase. Thus, the present study indicated that siCDCA5 anti-proliferative effect was exerted via arresting the cell cycle in G2 phase that was similar to the results obtained after TPI knockdown. This result was similar to previous results showing that CDCA5 knockdown could inhibit the proliferation of lung cancer cells and human oral squamous cell carcinoma (OSCC) cell lines $(22,23)$. Besides, CDCA5 knockdown could suppress the invasion ability of OSCC cell lines and arrest cells in G2 phase as well (23). The reason why CDCA5 knockdown could arrest cells in G2 phase may be associated with CDCA5 main function, which is to ensure the chromosome partitioning accurately (20). Our results indicated that TPI knockdown affected the malignant behavior of GC cell lines that might be related, at least in part, to CDCA5 silencing.

To the best of our knowledge, this is the first report exploring TPI and CDCA5 expression and function in gastric cancer, as well as their linking. Our results revealed some TPI oncogenic roles and the potential role of its downstream gene CDCA5 in GC cells. Hence, TPI and CDCA5 might be important potential tumor-markers related with GC development and might be considered as novel targets for the treatment of gastric cancer.

\section{Acknowledgements}

The present study was supported by the Natural Science Fund Project of Guangdong province, China (no. 2016A030313683), the Scientific and Technological plans of Guangdong province, China (no. 2013B021800065) and the Social Science and Technology Development Project of Dongguan, Guangdong Province, China (no. 2014108101051 and no. 2016108101039).

\section{References}

1. Yan S, Li B, Bai ZZ, Wu JQ, Xie DW, Ma YC, Ma XX, Zhao JH and Guo XJ: Clinical epidemiology of gastric cancer in Hehuang valley of China: A 10-year epidemiological study of gastric cancer. World J Gastroenterol 20: 10486-10494, 2014.

2. Meng X, Wang X and Ding C: Advances in lymph node metastasis of gastric cancer. Imaging J Integr Tradit West Med 13: 90-92, 2015

3. Maquat LE, Chilcote R and Ryan PM: Human triosephosphate isomerase cDNA and protein structure. Studies of triosephosphate isomerase deficiency in man. J Biol Chem 260: 3748-3753, 1985.

4. Qi YJ, He QY, Ma YF, Du YW, Liu GC, Li YJ, Tsao GS, Ngai SM and Chiu JF: Proteomic identification of malignant transformation-related proteins in esophageal squamous cell carcinoma. J Cell Biochem 104: 1625-1635, 2008.

5. Kim JE, Koo KH, Kim YH, Sohn J and Park YG: Identification of potential lung cancer biomarkers using an in vitro carcinogenesis model. Exp Mol Med 40: 709-720, 2008.
6. Chen WZ, Pang B, Yang B, Zhou JG and Sun YH: Differential proteome analysis of conditioned medium of BPH-1 and LNCaP cells. Chin Med J (Engl) 124: 3806-3809, 2011.

7. Linge A, Kennedy S, O'Flynn D, Beatty S, Moriarty P, Henry M, Clynes M, Larkin A and Meleady P: Differential expression of fourteen proteins between uveal melanoma from patients who subsequently developed distant metastases versus those who did Not. Invest Ophthalmol Vis Sci 53: 4634-4643, 2012.

8. Zhang ZQ, Li XJ, Liu GT, Xia Y, Zhang XY and Wen H: Identification of Annexin A1 protein expression in human gastric adenocarcinoma using proteomics and tissue microarray. World J Gastroenterol 19: 7795-7803, 2013.

9. Lin Z, Zhang X, Liu Z, Liu Q, Wang L, Lu Y, Liu Y, Wang M, Yang M, Jin X, et al: The distinct expression patterns of claudin-2, -6 , and -11 between human gastric neoplasms and adjacent nonneoplastic tissues. Diagn Pathol 8: 133, 2013.

10. Wang DG, Chen G, Wen XY, Wang D, Cheng ZH and Sun SQ: Identification of biomarkers for diagnosis of gastric cancer by bioinformatics. Asian Pac J Cancer Prev 16: 1361-1365, 2015.

11. Mikuriya K, Kuramitsu Y, Ryozawa S, Fujimoto M, Mori S, Oka M, Hamano K, Okita K, Sakaida I and Nakamura K: Expression of glycolytic enzymes is increased in pancreatic cancerous tissues as evidenced by proteomic profiling by twodimensional electrophoresis and liquid chromatography-mass spectrometry/mass spectrometry. Int J Oncol 30: 849-855, 2007.

12. Roth U, Razawi H, Hommer J, Engelmann K, Schwientek T, Müller S, Baldus SE, Patsos G, Corfield AP, Paraskeva C, et al: Differential expression proteomics of human colorectal cancer based on a syngeneic cellular model for the progression of adenoma to carcinoma. Proteomics 10: 194-202, 2010.

13. Ritterson Lew $C$ and Tolan DR: Targeting of several glycolytic enzymes using RNA interference reveals aldolase affects cancer cell proliferation through a non-glycolytic mechanism. J Biol Chem 287: 42554-42563, 2012.

14. Thongwatchara P, Promwikorn W, Srisomsap C, Chokchaichamnankit D, Boonyaphiphat $\mathrm{P}$ and Thongsuksai $\mathrm{P}$ : Differential protein expression in primary breast cancer and matched axillary node metastasis. Oncol Rep 26: 185-191, 2011.

15. Wang JW, Peng SY, Li JT, Wang Y, Zhang ZP, Cheng Y, Cheng DQ, Weng WH, Wu XS, Fei XZ, et al: Identification of metastasis-associated proteins involved in gallbladder carcinoma metastasis by proteomic analysis and functional exploration of chloride intracellular channel 1. Cancer Lett 281: 71-81, 2009.

16. Katayama M, Nakano H, Ishiuchi A, Wu W, Oshima R, Sakurai J, Nishikawa H, Yamaguchi S and Otsubo T: Protein pattern difference in the colon cancer cell lines examined by two-dimensional differential in-gel electrophoresis and mass spectrometry. Surg Today 36: 1085-1093, 2006.

17. Vander Heiden MG, Cantley LC and Thompson CB: Understanding the Warburg effect: The metabolic requirements of cell proliferation. Science 324: 1029-1033, 2009.

18. Shi JG: WRA: Whether the Warburg effect is the reason, result and the treatment of opportunity for cancer? Moden Oncol 6: 1459-1461, 2014.

19. Wei H, Guo L, Li L, Zhou Q and Wu Z: Mechanism of Warburg effect and its effect on tumor metastasis. Zhongguo Fei Ai Za Zhi 18: 179-183, 2015 (In Chinese).

20. Zhang $\mathrm{N}$ and Pati D: Sororin is a master regulator of sister chromatid cohesion and separation. Cell Cycle 11: 2073-2083, 2012.

21. Chang IW, Lin VC, He HL, Hsu CT, Li CC, Wu WJ, Huang CN, $\mathrm{Wu} \mathrm{TF}$ and $\mathrm{Li} \mathrm{CF}$ : CDCA5 overexpression is an indicator of poor prognosis in patients with urothelial carcinomas of the upper urinary tract and urinary bladder. Am J Transl Res 7: 710-722, 2015.

22. Nguyen MH, Koinuma J, Ueda K, Ito T, Tsuchiya E, Nakamura Y and Daigo Y: Phosphorylation and activation of cell division cycle associated 5 by mitogen-activated protein kinase play a crucial role in human lung carcinogenesis. Cancer Res 70: 5337-5347, 2010.

23. Tokuzen N, Nakashiro K, Tanaka H, Iwamoto K and Hamakawa H: Therapeutic potential of targeting cell division cycle associated 5 for oral squamous cell carcinoma. Oncotarget 7: 2343-2353, 2016. 